\title{
Geotecnologias e qualidade da água: estudos em reservatórios de abastecimento público
}

O uso e a ocupação do solo das bacias de contribuição dos reservatórios, além de outras atividades antrópicas, influenciam na qualidade das águas superficiais. Considerando-se os impactos causados pelas alterações da paisagem na qualidade da água, o conhecimento da dinâmica das mudanças de uso do solo nas bacias hidrográficas dos reservatórios de abastecimento público de regiões metropolitanas tornou-se uma atividade vital na gestão dos recursos hídricos. Tendo em vista a importância do gerenciamento do uso e ocupação do solo na qualidade da água, este artigo busca demonstrar como as geotecnologias podem contribuir na análise dos impactos das alterações no uso e ocupação do solo na qualidade da água em reservatórios de abastecimento público. A metodologia proposta envolve desde a caracterização e quantificação das classes de cobertura e uso do solo em diferentes épocas e sua correlação com os indicadores relativos à qualidade da água. O estudo ocorreu nos três reservatórios que compõem o sistema Paraopeba (Vargem das Flores, Serra Azul e Rio Manso), que é responsável por indicadores relativos a qualidade da água. multitemporais da dinâmica das classes de uso e ocupação do solo e métricas da paisagem no entorno dos reservatórios. 0 processamento e a análise dos dados foram realizados nos softwares gratuitos QGIS 3.8 e Fragstats 4.2. Os resultados demonstram que as alterações no uso e ocupação do solo refletem na qualidade da água em reservatórios de abastecimento público de região metropolitana. Foi produzido um diagnóstico dos impactos das alterações superficiais da paisagem na qualidade da água. Os mapas classificados da Plataforma MapBiomas são satisfatórios no que diz respeito à qualidade temática (índice Kappa), demonstrando a viabilidade de sua utilização em análises ambientais. Os resultados alcançados, somados a outras informações, certamente permitiriam aos órgãos públicos (executivo e o ministério público) tomar decisões mais assertivas no que dizem respeito à gestão e fiscalização dos recursos hídricos. A pesquisa desenvolvida é original e como a metodologia proposta se valeu apenas de ferramentas gratuitas e dados públicos de órgãos oficiais, acreditamos que essa medida pode contribuir A pesquisa desenvolvida é original
para a replicabilidade do trabalho.

Palavras-chave: Geotecnologias; Abastecimento de água; Uso e ocupação do solo; Ecologia da paisagem.

\section{Geotechnologies and water quality: studies in public supply reservoirs} \begin{abstract}
Regarding the contribution basins of the water reservoirs, the characteristics of land cover and land use, in addition to other anthropic activities, influences the quality of surface water. Thus,
getting knowledge about the local land-use as well as the impacts on water quality of public supply reservoirs triggered by landscape changes is a key activity towards the management of getting knowledge about the local land-use as well as the impacts on water quality of public supply reservoirs triggered by landscape changes is a key activity towards the management of
water resources within the hydrographic basins in metropolitan regions. Giving the importance of the theme, this article addresses a comprehensive demonstration of how geospatial technologies can contribute to the analysis of the impacts of changes in land use and occupation on water quality in public supply reservoirs. The methodological approach involves the characterization and quantification of the land cover and land use classes at different times and the correlation with the basic parameters of water quality. The study was developed in the three reservoirs of the Paraopeba Water Supply System (Vargem das Flores, Serra Azul, and Rio Manso), which supplies the majority of the population of the Metropolitan Region of Belo Horizonte -MG. The study used official and publicly available data. The methodology used multitemporal analyzes of the dynamics of the land cover and land use, and landscape metrics extracted of landcover classes surrounding the reservoirs. Data processing and analysis were performed using free software QGIS 3.8 and Fragstats 4.2. A diagnosis of the impacts of superficia landscape changes on water quality was produced. Findings show that landscape changes, either the pattern of the classes or landscape metrics reflect on water quality in public supply reservoirs in the metropolitan region. The classified maps of the MapBiomas Platform are satisfactory concerning thematic quality (Kappa index), moreover, the results demonstrated the reservoirs in the metropolitan region. The classified maps of the MapBiomas Platform are satisfactory concerning thematic quality (Kappa index), moreover, the results demonstrated the
feasibility of their use in environmental analyzes. The results achieved, added to other information, would certainly allow public bodies (executive and public prosecutors) to make more feasibility of their use in environmental analyzes. The results achieved, added to other information, would certainly allow public bodies (executive and public prosecutors) to make more
assertive decisions concerning the management and inspection of water resources. This research is original and structured to allow technology transferring due to a methodology based on open source tools and public data.
\end{abstract}

Keywords: Geotechnology; Water supply; Land cover; Land use; Landscape ecology.

Topic: Tecnologia, Modelagem e Geoprocessamento

Reviewed anonymously in the process of blind peer.

Marcos de Paulo Ramos (iD

Centro Federal de Educação Tecnológica de Minas Gerais, Brasil http://lattes.cnpq.br/6704718932869954

http://orcid.org/0000-0003-3296-6590

marcosramos.ufv@gmail.com

Ana Luiza Cunha Soares

Universidade Federal de Minas Gerais, Brasil

http://lattes.cnpq.br/4490719282322188

http://orcid.org/0000-0002-0111-5016

analulucunha@gmail.com

Rodrigo Affonso de Albuquerque Nobrega Universidade Federal de Minas Gerais, Brasil http://lattes.cnpq.br/7158751194696023

http://orcid.org/0000-0001-7058-5903

raanobrega@ufmg.br

DOI: $10.6008 / C B P C 2179-6858.2020 .007 .0055$
Received: 03/12/2020

Approved: 23/12/2020
Marcony de Paulo Ramos (iD

Universidade Federal da Bahia, Brasil

http://lattes.cnpq.br/2233533488094532

http://orcid.org/0000-0002-7423-7727

marconypaulo@yahoo.com.br

André Luiz Fonseca Naime (iD

Instituto Brasileiro do Meio Ambiente e dos Recursos Renováveis, Brasil http://lattes.cnpq.br/1184490161532508

http://orcid.org/0000-0001-9281-1844

andre.naime.ibama@gmail.com

Lyssandro Norton Siqueira (iD)

Universidade Federal de Minas Gerais, Brasil

http://lattes.cnpq.br/9263657919218752

http://orcid.org/0000-0003-2530-0272

lyssandro.norton@gmail.com

\section{Referencing this:}

RAMOS, M. P.; SOARES, A. L. C.; NOBREGA, R. A. A.; RAMOS, M. P.; NAIME, A. L. F.; SIQUEIRA, L. N.. Geotecnologias e qualidade da água: estudos em reservatórios de abastecimento público. Revista Ibero Americana de Ciências Ambientais, v.11, n.7, p.722-739, 2020. DOI: http://doi.org/10.6008/CBPC2179-6858.2020.007.0055 


\section{INTRODUÇÃO}

A qualidade das águas superficiais pode ser alterada por diversos fatores, podendo se destacar a explosão demográfica e os conflitos relacionados ao uso do solo, uma vez que causam o maior comprometimento dos recursos naturais. Portanto, torna-se necessário a gestão integrada destes, com foco em recursos hídricos, solo, cobertura vegetal e biodiversidade.

As bacias hidrográficas que contemplam regiões metropolitanas representam uma importante fonte de água para a população nela inserida. Nestas bacias geralmente são construídos reservatórios para uso destinado ao abastecimento público, irrigação, geração de energia, regulação de vazão em períodos de chuva, dessedentação animal, pesca, navegação, lazer, dentre outros (GOMES, 2008). Essas bacias e seus corpos receptores estão submetidos a pressões antrópicas variadas como mudanças climáticas e alterações de uso do solo que agravam os impactos sobre os recursos naturais.

A diminuição do volume de água dos reservatórios, somada aos efeitos da antropização acelerada das bacias hidrográficas, pode resultar em perda da qualidade da água, com consequências para a população local e aumento dos gastos de tratamento para abastecimento público (GOMES, 2008). A deterioração da qualidade dos recursos hídricos de um reservatório pode levar à eutrofização, acarretando florações de algas, diminuição do oxigênio na água, mortandade de peixes, mau cheiro e crescimento acelerado de macrófitas aquáticas (VON SPERLING et al., 2008).

O uso e a ocupação do solo da bacia de contribuição do reservatório também influenciam na qualidade da água, uma vez que, em períodos de precipitação, os solos mais vulneráveis às erosões, representam um maior carreamento de partículas e impurezas para os corpos hídricos. Também, a lixiviação de nutrientes e poluentes pode contaminar os rios e os lençóis freáticos. Além disso, a impermeabilização excessiva, aumenta a velocidade de escoamento e dificulta a recarga dos aquíferos. Outras atividades antrópicas, como a exploração de minério, podem ocasionar a contaminação dos corpos hídricos com metais pesados. Por fim, o lançamento, sem tratamento, de efluentes domésticos e industriais pode causar enfermidades e o aumento de matéria orgânica na água, podendo resultar em degradação da qualidade da água até alcançar o nível de eutrofização.

Muitos estudos têm mostrado a relação entre diferentes usos do solo e influências na qualidade da água. Fisher et al. (2000) descobriram que o uso do solo teve impactos na qualidade das águas superficiais em Xangai, na China. Também na China, Feng et al. (2004) caracterizaram a rápida urbanização e a recente recuperação de áreas úmidas costeiras como principais contribuintes para a contaminação por metais pesados do rio Yangtze. Um estudo nos Estados Unidos descobriu que a água das bacias agrícolas continha concentrações de nitrato e fosfato aproximadamente nove vezes maiores que as das bacias florestais (BINKLEY et al., 1999). Sendo assim, a relação entre uso do solo e a qualidade da água é bastante complexa, estando intimamente relacionada a variações espaciais e temporais (YE et al., 2014).

A área de estudo desta pesquisa é composta por três reservatórios que compõem o sistema Paraopeba. Este é responsável por parte do abastecimento da população da Região Metropolitana de Belo 
Horizonte (RMBH). Os reservatórios de Vargem das Flores, Serra Azul e Rio Manso, apesar de possuírem capacidade máxima de aproximadamente 276 milhões de $\mathrm{m}^{3}$ de água, operaram em junho de 2017 com apenas $59,2 \%$ do seu volume total, o que configura os reflexos da crise hídrica dos anos anteriores (COPASA, 2017). As áreas no entorno desses reservatórios sofreram consideráveis mudanças no padrão de cobertura e uso do solo e, considerando os impactos causados por tais alterações na qualidade da água, conhecer e analisar a dinâmica dessas mudanças nas bacias hidrográficas dos reservatórios é extremamente importante na gestão dos recursos hídricos.

A integração de geotecnologias, um conjunto de tecnologias para coleta, processamento, análise e disponibilização de informações geográficas, como o sensoriamento remoto e sistemas de informações geográficas (SIG), oferece técnicas que vêm se destacando nos procedimentos de levantamentos e mapeamento de áreas (ROCHA, 2002). Nesse contexto, o geoprocessamento e as métricas de paisagem surgem como instrumentos para auxiliar na quantificação e análise da dinâmica de uso solo e avaliar eventuais impactos sobre a qualidade da água.

Segundo Couto (2004), o termo "métricas da paisagem" refere-se exclusivamente a índices desenvolvidos para padrões de mapas categóricos e são algoritmos que quantificam características espaciais de fragmentos. A análise das métricas de paisagem dá maior clareza sobre a situação ambiental da área de estudo. Metzger (2001) destaca alguns termos utilizados na ecologia da paisagem: [1] Corredores: Áreas homogêneas (numa determinada escala) de uma unidade da paisagem, que se distinguem das unidades vizinhas e que apresentam disposição espacial linear. Em estudos de fragmentação, considera-se corredor apenas os elementos lineares que ligam dois fragmentos anteriormente conectados; [2] Fragmento: Uma mancha originada por fragmentação, isto é, por subdivisão, promovida pelo homem, de uma unidade que inicialmente apresentava-se sob forma contínua, como uma matriz; [3] Manchas: Áreas homogêneas (numa determinada escala) de uma unidade da paisagem, que se distinguem das unidades vizinhas e têm extensões espaciais reduzidas e não-lineares; [4] Matriz: Em geral essa unidade pode ser reconhecida por recobrir a maior parte da paisagem (ou seja, sendo a unidade dominante em termos de recobrimento espacial), ou por ter um maior grau de conexão de sua área (isto é, um menor grau de fragmentação).

Uma vez que alterações do uso e cobertura do solo podem interferir na qualidade da água, uma das formas de acompanhar o estado geral de qualidade da água é através da utilização de Índices de Qualidade da água (IQA), que representam em um único indicador a influência de diferentes parâmetros de qualidade da água e trazem informações sobre sua qualidade para os tomadores de decisão (LKR et al., 2020).

Nesse sentido, esta pesquisa visou demonstrar como as geotecnologias podem contribuir na análise dos impactos das alterações no uso e ocupação do solo na qualidade da água em reservatórios de abastecimento público de Região Metropolitana. Foram utilizados dados referentes aos anos de 2007 e 2017 para o levantamento das informações necessárias à análise. Esse período foi escolhido porque em 2017 a $\mathrm{RMBH}$ foi acometida por uma forte crise hídrica, sendo escolhido o referido ano como referência e 10 anos antes para comparação. Para tanto, foram traçados os seguintes objetivos específicos: Analisar o potencial de uso de programas computacionais (software) e dados gratuitos na gestão dos recursos hídricos; Analisar 
a expansão urbana e a fragmentação florestal da área de estudo; Analisar os impactos das alterações do uso e ocupação do solo e da expansão urbana e fragmentação florestal na qualidade da água; Elencar os desafios da utilização das geotecnologias na gestão dos recursos hídricos.

\section{REVISÃO TEÓRICA}

\section{Área de estudo}

O abastecimento de água potável da Região Metropolitana de Belo Horizonte - RMBH/MG é realizado basicamente através de um sistema integrado, que é gerido pela Companhia de Saneamento de Minas Gerais - COPASA. A captação de água é realizada diretamente no Rio das Velhas, no Rio Paraopeba e em três reservatórios artificiais: o Serra Azul, o Rio Manso e o Vargem das Flores (todos localizados na bacia do Rio Paraopeba). Com o rompimento da barragem de rejeitos de mineração da empresa Vale, no município de Brumadinho/MG, os pontos de captação de água diretamente no Rio Paraopeba foram contaminados, sendo que os três reservatórios passaram a ser as principais fontes de água para o abastecimento de grande parte da Região Metropolitana de Belo Horizonte durante o período crítico do desastre.

Com base na importância dos três reservatórios para a Região Metropolitana de Belo Horizonte, e nas substanciais diferenças no padrão de uso e ocupação do solo nas áreas de entorno dos reservatórios, as sub-bacias hidrográficas dos três reservatórios foram escolhidas como área de estudo (Figura 1).

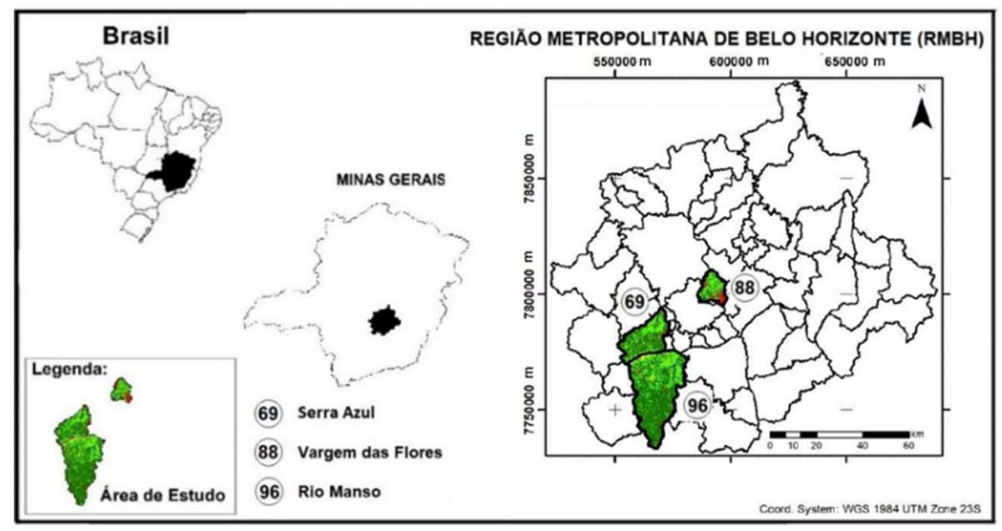

Figura 1: Área de estudo.

O reservatório Serra Azul está localizado na porção oeste da RMBH. A região da bacia hidrográfica contribuinte abrange parcialmente os municípios de Mateus Leme, Igarapé e Juatuba, sendo que a área da bacia hidrográfica de contribuição até a Estação de Monitoramento BP069 é de aproximadamente 274,45 $\mathrm{km}^{2}$. A bacia do reservatório caracteriza-se principalmente pela ocorrência de pastos, pastos sujos e áreas cultivadas. A atividade da região, que envolve maiores recursos financeiros e é responsável pelos maiores prejuízos ambientais, é a exploração mineral (CARVALHO, 2002).

$\mathrm{O}$ reservatório de Vargem das Flores se insere na porção centro-oeste da RMBH, em área de manancial e proteção ambiental de alcance metropolitano. Sua área está totalmente inserida na RMBH e apresenta atividades associadas ao turismo, ocupação residencial de renda alta (condomínios), bem como sofre pressões de expansão urbana. O reservatório de Vargem das Flores está localizado entre os municípios 
de Betim e Contagem e a área da bacia de hidrográfica de contribuição até a Estação de Monitoramento BP088 é de aproximadamente $124,14 \mathrm{~km}^{2}$.

Por sua vez, o reservatório Rio Manso é o terceiro que compõe o Sistema Paraopeba. A região da bacia hidrográfica contribuinte abrange parcialmente os municípios de Brumadinho, Rio Manso, Itatiaiuçu, Crucilândia e Bonfim, sendo que a área da bacia de hidrográfica de contribuição até a Estação de Monitoramento BP096 de aproximadamente $672,66 \mathrm{~km}^{2}$. Na bacia do reservatório são observadas atividades ligadas à exploração minerária e a região tem expressiva representatividade na produção agrícola de alimentos, abastecendo a RMBH (BELO HORIZONTE, 2017).

Embora estejam inseridas em contextos geográficos distintos, cabe ressaltar que conflitos de uso do solo são observados no entorno dos três reservatórios. É nesse sentido que a pesquisa recorre às análises multitemporais e métricas da paisagem para caracterizar as mudanças no padrão das classes de uso e cobertura do solo, bem como identificar como essas mudanças podem influenciar na qualidade da água.

Após escolher a área de estudo e estabelecer uma base de dados georreferenciada, foram selecionadas as Estações de Monitoramento do Projeto de Águas de Minas do Instituto Mineiro de Gestão das Águas - IGAM. As primeiras estações de monitoramento à jusante de cada reservatório foram escolhidas sendo: BP069 - Reservatório Serra Azul; BP088 - Reservatório Vargem das Flores; e BP096 - Reservatório Rio Manso (BP - Bacia Paraopeba). No software QGIS delimitou-se a área da bacia de contribuição para cada uma das estações escolhidas e calculou-se a distância entre o reservatório e a estação de monitoramento. O IGAM, a partir dos resultados dos parâmetros físicos, químicos e biológicos obtidos nas estações de monitoramento, apresentou nos relatórios de avaliação da qualidade das águas os seguintes valores de IQA para os anos de 2007 e 2017 (Tabela 1).

Tabela 1: Índice de Qualidade da Água (IQA) para as estações BP069, BP088 e BP096.

\begin{tabular}{lll}
\hline Estação de Monitoramento & IQA (2007) & IQA (2017) \\
\hline BP069 & 37 & 54 \\
BP088 & 90 & 83 \\
BP096 & 54 & 40 \\
\hline
\end{tabular}

Fonte: IGAM (2008; 2018).

Em complementação ao estudo, foram utilizados na análise os dados do Sistema Nacional de Informações sobre Saneamento - SNIS referentes aos índices de coleta e tratamento de esgoto dos municípios que compõem as bacias hidrográficas de contribuição dos três reservatórios referentes aos anos de 2007 e 2017 (Tabela 2). O Índice de coleta de esgoto (IN015) é a razão entre o volume de esgoto tratado pelo volume de água consumido multiplicada por cem e o Índice de tratamento de esgoto (IN016) é a razão entre o volume de esgoto tratado. O volume coletado também é multiplicado por cem.

Tabela 2: Índice de coleta e tratamento de esgoto dos municípios que compõem os reservatórios.

\begin{tabular}{lllllll}
\hline \multirow{2}{*}{ Reservatórios } & $\begin{array}{l}\text { Município } \\
\text { (\% da área }\end{array}$ & $\begin{array}{l}\text { Índice de coleta de esgoto } \\
\text { (IN015) }\end{array}$ & $\begin{array}{l}\text { Índice de tratamento de esgoto } \\
\text { (IN016) }\end{array}$ \\
\cline { 2 - 6 } & reservatório) & $\mathbf{2 0 0 7}$ & $\mathbf{2 0 1 7}$ & $\mathbf{2 0 0 7}$ & $\mathbf{2 0 1 7}$ \\
\hline \multirow{3}{*}{ Serra Azul } & Igarapé (64\%) & $21,33 \%$ & $42,57 \%$ & $0 \%$ & $0 \%$ \\
& Juatuba (5\%) & $32,23 \%$ & $26,87 \%$ & $5,91 \%$ & $58,6 \%$ \\
& Mateus Leme (50\%) & - & $42,66 \%$ & - & $76,17 \%$
\end{tabular}




\begin{tabular}{|c|c|c|c|c|c|c|}
\hline Vargem & das & Betim (38\%) & $66,49 \%$ & $56,07 \%$ & $3,99 \%$ & $91,99 \%$ \\
\hline \multirow[t]{3}{*}{ Flores } & & Contagem (55\%) & $61,56 \%$ & $71,91 \%$ & $44,1 \%$ & $95,74 \%$ \\
\hline & & Bonfim $(11,5 \%)$ & $54,06 \%$ & $60,21 \%$ & $0 \%$ & $0 \%$ \\
\hline & & Brumadinho $(14,5)$ & $7,14 \%$ & $61,95 \%$ & $100 \%$ & $18,56 \%$ \\
\hline \multirow[t]{3}{*}{ Rio Manso } & & Crucilândia (88,6\%) & - & $100 \%$ & - & $50 \%$ \\
\hline & & Itatiaiuçu $(51,33 \%)$ & - & $79,27 \%$ & - & $0 \%$ \\
\hline & & Rio Manso $(99,9 \%)$ & - & - & - & - \\
\hline
\end{tabular}

Fonte: SNIS (2020).

\section{Recursos materiais}

A seleção dos recursos materiais foi de fundamental importância para o bom desenvolvimento da metodologia. Em atendimento a um dos objetivos da pesquisa, e por acreditarmos que essa medida pode contribuir para facilitar a replicabilidade do trabalho, foram levadas em consideração a existência e a disponibilidade de dados e software gratuitos, bem como a adequação desses para a finalidade da análise proposta.

Os recursos materiais e computacionais utilizados durante a realização dos estudos foram as ferramentas QGIS 3.8 para as operações de geoprocessamento e Fragstats 4.2.1 para a análise de métricas da paisagem, um computador pessoal e a base cartográfica digital da área de estudo, conforme descrito a seguir (Tabela 3).

Para a caracterização e avaliação da qualidade das águas superficiais da bacia hidrográfica de contribuição dos reservatórios foi utilizado o Índice de Qualidade da Água (IQA) calculado para os anos de 2007 e 2017 pelo IGAM através do Programa Águas de Minas.

Tabela 3: Informações gerais sobre a fonte de dados utilizada.

\begin{tabular}{|c|c|c|}
\hline Dados & onte & formações gerais \\
\hline $\begin{array}{l}\text { Limites municipais } \\
\text { e regionais, } \\
\text { modelo digital de } \\
\text { elevação e outros }\end{array}$ & $\begin{array}{l}\text { IDE-Sisema } \\
\text { Infraestrutura de } \\
\text { Dados Espaciais do } \\
\text { Sistema Estadual de } \\
\text { Meio Ambiente e } \\
\text { Recursos Hídricos }\end{array}$ & $\begin{array}{l}\text { - Plataforma criada pelo Sistema Estadual de Meio Ambiente e Recursos Hídricos } \\
\text { de Minas Gerais (Sisema); } \\
\text { - Permite o download gratuito nos formatos kml e shapefile; } \\
\text { - Abrangência: estado de Minas Gerais; } \\
\text { Acesso: http://idesisema.meioambiente.mg.gov.br/ }\end{array}$ \\
\hline $\begin{array}{l}\text { Mapas de uso e } \\
\text { cobertura do solo } \\
\text { de } 2007 \text { e } 2017\end{array}$ & $\begin{array}{l}\text { MapBiomas } \\
\text { Projeto de } \\
\text { Mapeamento Anual } \\
\text { da Cobertura e Uso } \\
\text { do Solo do Brasil }\end{array}$ & $\begin{array}{l}\text { - Processamento em nuvem; } \\
\text { - Classificadores automatizados desenvolvidos e operados na plataforma Google } \\
\text { Earth Engine; } \\
\text { - Mapas anuais de cobertura e uso da terra do Brasil; } \\
\text { - Rede colaborativa com especialistas de diversas áreas; } \\
\text { Acesso: http://plataforma.mapbiomas.org/. }\end{array}$ \\
\hline $\begin{array}{l}\text { Informações gerais } \\
\text { sobre os } \\
\text { reservatórios } \quad \text { e } \\
\text { índices } \\
\text { qualidade da água }\end{array}$ & $\begin{array}{l}\text { Projeto Águas de } \\
\text { Minas do IGAM e } \\
\text { COPASA }\end{array}$ & $\begin{array}{l}\text { - Projeto responsável pelo monitoramento da qualidade das águas superficiais e } \\
\text { subterrâneas de Minas Gerais. } \\
\text { Acesso: http://portalinfohidro.igam.mg.gov.br/monitoramento-de-qualidade- } \\
\text { das-aguas } \\
\text { - Companhia de Saneamento de Minas Gerais - COPASA }\end{array}$ \\
\hline $\begin{array}{l}\text { Informações gerais } \\
\text { sobre índices de } \\
\text { coleta } \\
\text { tratamento de } \\
\text { esgoto }\end{array}$ & $\begin{array}{l}\text { Sistema Nacional de } \\
\text { Informações sobre } \\
\text { Saneamento - SNIS }\end{array}$ & $\begin{array}{l}\text {-É um sistema do Ministério do Desenvolvimento Regional que reúne informações } \\
\text { e indicadores sobre a prestação dos serviços de Água, Esgotos, manejo de Resíduos } \\
\text { Sólidos e manejo de Águas Pluviais, provenientes dos prestadores que operam no } \\
\text { Brasil. } \\
\text { Acesso: www.snis.gov.br }\end{array}$ \\
\hline
\end{tabular}

\section{METODOLOGIA}

Considerando a importância do gerenciamento do uso e ocupação do solo na qualidade da água (CAREY et al., 2011; URIARTE et al., 2011; WILSON et al., 2011), a metodologia proposta é uma sequência de 
análises comparativas de indicadores relativos à qualidade da água. Por seu turno, as propriedades geográficas das classes de cobertura do solo na área de estudo em dois momentos distintos são referentes aos anos de 2007 e 2017 (Figura 2).

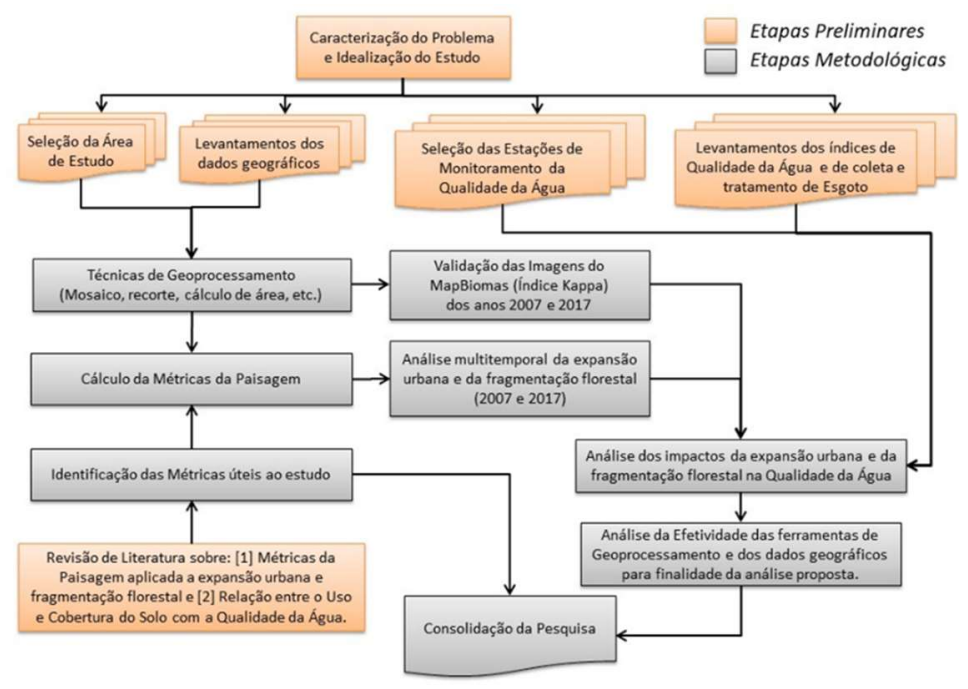

Figura 2: Fluxograma síntese da metodologia proposta.

As etapas preliminares, mais especificamente na caracterização do problema e idealização do estudo, foram apoiadas por intensa revisão de literatura e levantamento de dados. Posteriormente, foi selecionada a área de estudo e as respectivas estações de monitoramento da qualidade de água. Nas etapas metodológicas, foram utilizadas técnicas de geoprocessamento na preparação dos dados e na identificação e cálculo das métricas úteis ao estudo. Em seguida, foi analisada a expansão urbana e da fragmentação florestal na área de estudo e, paralelamente, foi verificada a qualidade temática dos mapas. Por fim, foi analisado o impacto da fragmentação e da expansão urbana na qualidade da água, momento em que também se analisou a efetividade das ferramentas de geoprocessamento.

\section{Identificação das métricas para estudo da expansão urbana e da fragmentação florestal}

A proposição deste estudo se vale da Ecologia da Paisagem para analisar, quantificar e avaliar a estrutura e as mudanças na paisagem. Dentre eles, pode-se destacar os que estudaram a expansão urbana (SILVA et al., 2012; BARBOSA et al., 2009) e os que analisaram a fragmentação Florestal (SAITO et al., 2016; BEZERRA et al., 2011). As métricas determinantes no estudo da expansão urbana e da fragmentação florestal foram: área total da classe, percentagem de área, número de polígonos, relação perímetro/área e índice de forma. Mais informações sobre esses indicadores podem ser acessadas no estudo de Couto (2004), constante das referências deste texto.

\section{Técnicas de geoprocessamento e preparação das informações}

Para a manipulação, integração e análises dos dados geográficos foram utilizadas técnicas tradicionais de geoprocessamento como a conversão de sistemas de coordenadas e de referências, conversão dos dados em diferentes formatos, mosaico, recorte geográfico, delimitação das bacias 
hidrográficas, reclassificação de mapas, cálculos de área etc.

Os limites municipais e regionais, bem como o modelo digital de elevação utilizado para delimitação das bacias, foram obtidos na Plataforma IDE-Sisema (SISEMA, 2019). Os mapas de cobertura e uso do solo disponíveis na plataforma MapBiomas possuem várias classes referentes a esses elementos (Pastagem; Formação Florestal; Formação Campestre; Mosaico de Agricultura e Pastagem; Floresta Plantada; Rio; Infraestrutura Urbana; Mineração; e Afloramento Rochoso), no entanto, para tornar a análise viável, essas classes foram reagrupadas em cinco novos grupos (Infraestrutura Urbana; Pastagem/Cultura; Mata; Água; e Mineração/Solo Exposto), seguindo critérios semelhantes aos definidos pelo Manual Técnico de Uso da Terra (IBGE, 2013).

A análise e validação dos mapas classificados oriundos da Plataforma MapBiomas, ou seja, o controle de qualidade da classificação das referidas imagens foi desenvolvido utilizando a estatística Kappa. O método é tradicionalmente utilizado para avaliar a concordância entre a verdade terrestre e o mapa temático, de forma global, integrando métricas de qualidade temática de todas as classes por meio de uma matriz de confusão (MOREIRA, 2003).

\section{Cálculo das Métricas da Paisagem}

Após a verificação da qualidade temática dos mapas de uso e ocupação do solo, as métricas foram calculadas no software Fragstats 4.2. Os arquivos de dados utilizados para análise da expansão urbana e a da fragmentação florestal foram os mapas classificados dos três reservatórios para os anos de 2007 e 2017, reclassificadas dos originais obtidos do projeto MapBiomas. Esse processo foi realizado a partir do exame das métricas supracitadas anteriormente.

Os resultados foram posteriormente organizados e tabulados, de forma a facilitar a análise comparativa para os dois períodos estudados. As mudanças na estrutura da paisagem, analisada através da quantificação dos valores das métricas para as classes de uso e ocupação do solo, permitem inferir sobre a expansão urbana e sobre a fragmentação florestal das bacias hidrográficas dos reservatórios analisados.

\section{Análise dos índices de qualidade da água}

Dos dados de monitoramento de qualidade do Programa Águas de Minas para os anos-base 2007 e 2017, disponíveis para o estudo, foi adotado o IQA, que é um índice criado pela National Sanitation Foundation, dos Estados Unidos, através de pesquisas de opinião junto a vários especialistas da área. O IQA reúne nove parâmetros, considerados mais representativos para a caracterização da qualidade das águas: coliformes fecais (termotolerantes), pH, demanda bioquímica de oxigênio, nitrato, fosfato total, temperatura da água, turbidez, sólidos totais e oxigênio dissolvido (COSTA et al., 2015). O IQA é utilizado como um índice que classifica a qualidade dos cursos d'água, conforme categorias fornecidas pelo IGAM (Tabela 4).

Tabela 4: Classificação de qualidade da água.

\begin{tabular}{ll}
\hline Categoria & Ponderação \\
\hline Excelente & $90<$ IQA $\leq 100$ \\
Bom & $70<$ IQA $\leq 90$ \\
\hline
\end{tabular}




$\begin{array}{ll}\text { Médio } & 50<\mathrm{IQA} \leq 70 \\ \text { Ruim } & 25<\mathrm{IQA} \leq 50 \\ \text { Muito Ruim } & 0<\mathrm{IQA} \leq 25\end{array}$

Fonte: Adaptado IGAM (2012).

Análise dos índices de coleta e tratamento de esgoto

Nesta etapa, foram analisadas as variações dos índices de coleta de esgoto (IN015) e o índice de tratamento de esgoto (IN016) para os municípios que compõem as bacias hidrográficas de contribuição dos três reservatórios referentes aos anos de 2007 e 2017. Os dados foram extraídos do Sistema Nacional de Informações sobre Saneamento - SNIS, um sistema do Ministério do Desenvolvimento Regional.

\section{Análise do impacto da expansão urbana e da fragmentação florestal na qualidade da água}

Para esta etapa foram analisadas quantitativamente as variações dos índices de qualidade da água, os índices de coleta e tratamento de esgoto e as métricas de paisagem nos anos de 2007 e 2017, nos três reservatórios da RMBH, correlacionando a expansão urbana e a fragmentação florestal com as variações do índice de qualidade da água para o mesmo período. Foram calculadas as principais métricas para cada um dos três reservatórios e avaliados os impactos das mudanças dessas métricas na qualidade da água para os anos em análise.

\section{Análise de efetividade das ferramentas de geoprocessamento e dos dados geográficos}

Nesta etapa foram elencadas as vantagens, as desvantagens e os desafios da utilização das ferramentas de geoprocessamento e de dados geográficos gratuitos na metodologia proposta. Essa análise se deu através da avaliação da qualidade temática das imagens utilizadas e da análise da eficiência dos dados utilizados para a finalidade proposta.

\section{RESULTADOS}

Análise e validação das imagens de uso e cobertura do solo da Plataforma MapBiomas

Antes de realizar o controle de qualidade da classificação das imagens com as classes de uso e cobertura do solo do MapBiomas, estas tiveram suas classes reagrupadas em cinco novas categorias, conforme apresentado na Tabela 5.

Em seguida, foi analisado o controle de qualidade dos mapas classificados do MapBiomas utilizandose a estatística Kappa para os reservatórios Serra Azul/Estação BP069, Vargem das Flores/Estação BP088 e Rio Manso/Estação BP096, para os anos de 2007 e 2017. No software QGIS foram distribuídos aleatoriamente, de acordo com a extensão de cada bacia, 622 pontos de controles para validar o mapa temático, 200 pontos de controle para a bacia hidrográfica do Reservatório Serra Azul (Tabela 6), 98 pontos para o Reservatório Vargem das Flores (Tabela 7) e 324 pontos para o Reservatório Rio Manso (Tabela 8). Em seguida, foram criados as matrizes de transição e o cálculo dos índices Kappa para os anos analisados. 
Tabela 5: Irregularidades apontadas para os estudos de caso escolhidos.

\begin{tabular}{|c|c|c|}
\hline Classes & Reagrupamento & Classes originais (MapBiomas) \\
\hline 1 & Infraestrutura Urbana & Infraestrutura Urbana \\
\hline \multirow{2}{*}{2} & \multirow{2}{*}{ Pastagem/Cultura } & Pastagem \\
\hline & & Mosaico de Agricultura e Pastagem \\
\hline \multirow{3}{*}{3} & \multirow{3}{*}{ Mata } & Formação Florestal \\
\hline & & Floresta Plantada \\
\hline & & Formação Campestre \\
\hline 4 & Água & Rio. Lago e Oceano \\
\hline \multirow{2}{*}{5} & \multirow{2}{*}{ Mineração/Solo Exposto } & Mineração \\
\hline & & Afloramento Rochoso \\
\hline
\end{tabular}

Tabela 6: Matriz de confusão e Índice Kappa - Reservatório Serra Azul - 2007 (a) e 2017 (b).

Ano: 2007

\begin{tabular}{lllllll}
\hline CLASSES & $\mathbf{1}$ & $\mathbf{2}$ & $\mathbf{3}$ & $\mathbf{4}$ & $\mathbf{5}$ & Total \\
\hline 1 - Infraestrutura Urbana & $\mathbf{1}$ & 2 & 0 & 0 & 0 & 3 \\
2 - Pastagem/Cultura & 2 & $\mathbf{1 0 2}$ & $\mathbf{7}$ & 0 & 0 & 111 \\
3 - Mata & 0 & 17 & $\mathbf{5 7}$ & 0 & 2 & 76 \\
4 - Água & 0 & 0 & 0 & $\mathbf{6}$ & 0 & 6 \\
5 - Mineração/Solo Exposto & 0 & 1 & 0 & 0 & $\mathbf{3}$ & 4 \\
\hline Total & 3 & 122 & 64 & 6 & 5 & $\mathbf{2 0 0}$ \\
\hline Índice Kappa $=0,712$ (Muito boa) & & & & &
\end{tabular}

(a)

Tabela 7: Matriz de confusão e Índice Kappa - Reservatório Serra Azul - 2007 (a) e 2017 (b).

Ano: 2007

\begin{tabular}{lllllll}
\hline CLASSES & $\mathbf{1}$ & $\mathbf{2}$ & $\mathbf{3}$ & $\mathbf{4}$ & $\mathbf{5}$ & Total \\
\hline 1 - Infraestrutura Urbana & $\mathbf{1 0}$ & 5 & 0 & 0 & 0 & 15 \\
2 - Pastagem/Cultura & 0 & $\mathbf{2 4}$ & 3 & 0 & 0 & 27 \\
3 - Mata & 1 & 7 & $\mathbf{3 8}$ & 0 & 0 & 46 \\
4 - Água & 0 & 0 & 0 & $\mathbf{8}$ & 0 & 8 \\
5 - Mineração/Solo Exposto & 0 & 2 & 0 & 0 & $\mathbf{0}$ & 2 \\
\hline Total & 11 & 38 & 41 & 8 & 0 & $\mathbf{9 8}$ \\
\hline
\end{tabular}

Índice Kappa = 0,727 (Muito boa)

(a)

\begin{tabular}{lllllll} 
Ano: 2017 & & & & & \\
\hline CLASSES & $\mathbf{1}$ & $\mathbf{2}$ & $\mathbf{3}$ & $\mathbf{4}$ & $\mathbf{5}$ & Total \\
\hline 1 & $\mathbf{0}$ & 7 & 1 & 0 & 0 & 8 \\
2 & 1 & $\mathbf{9 6}$ & 9 & 0 & 0 & 106 \\
3 & 0 & 13 & $\mathbf{6 1}$ & 0 & 1 & 75 \\
4 & 0 & 0 & 0 & $\mathbf{5}$ & 0 & 5 \\
5 & 0 & 1 & 0 & 1 & $\mathbf{4}$ & 6 \\
\hline Total & 1 & 117 & 71 & 6 & 5 & $\mathbf{2 0 0}$ \\
\hline
\end{tabular}

Índice Kappa = 0,694 (Muito boa)

(b)

\begin{tabular}{lllllll} 
Ano: 2017 & & & & & \\
\hline CLASSES & $\mathbf{1}$ & $\mathbf{2}$ & $\mathbf{3}$ & $\mathbf{4}$ & $\mathbf{5}$ & Total \\
\hline 1 & $\mathbf{1 2}$ & 10 & 1 & 0 & 0 & 23 \\
2 & 0 & $\mathbf{1 8}$ & 6 & 0 & 0 & 24 \\
3 & 1 & 7 & $\mathbf{3 6}$ & 0 & 0 & 44 \\
4 & 0 & 0 & 0 & $\mathbf{6}$ & 0 & 6 \\
5 & 0 & 1 & 0 & 0 & $\mathbf{0}$ & 1 \\
\hline Total & 13 & 36 & 43 & 6 & 0 & $\mathbf{9 8}$
\end{tabular}

Índice Kappa = 0,609 (Muito boa)

(b)

Tabela 8: Matriz de confusão e Índice Kappa - Reservatório Rio Manso - 2007 (a) e 2017 (b). Ano: 2007

\begin{tabular}{lllllll}
\hline CLASSES & $\mathbf{1}$ & $\mathbf{2}$ & $\mathbf{3}$ & $\mathbf{4}$ & $\mathbf{5}$ & Total \\
\hline 1 - Infraestrutura Urbana & $\mathbf{2}$ & 5 & 0 & 0 & 1 & 8 \\
2 - Pastagem/Cultura & 2 & $\mathbf{1 6 2}$ & 4 & 0 & 9 & 177 \\
3 - Mata & 0 & 49 & $\mathbf{6 8}$ & 0 & 4 & 121 \\
4 - Água & 0 & 1 & 0 & $\mathbf{1 0}$ & 0 & 11 \\
5 - Mineração/Solo Exposto & 0 & 1 & 0 & 0 & $\mathbf{6}$ & 7 \\
\hline Total & 4 & 218 & 72 & 10 & 20 & $\mathbf{3 2 4}$ \\
\hline
\end{tabular}

Índice Kappa = 0,571 (Boa)

(a)

\begin{tabular}{lllllll} 
Ano: 2017 & & & & & & \\
\hline CLASSES & $\mathbf{1}$ & $\mathbf{2}$ & $\mathbf{3}$ & $\mathbf{4}$ & $\mathbf{5}$ & Total \\
\hline 1 & $\mathbf{3}$ & 6 & 0 & 0 & 0 & 9 \\
2 & 0 & $\mathbf{1 6 9}$ & 5 & 0 & 6 & 180 \\
3 & 1 & 44 & $\mathbf{6 7}$ & 0 & 3 & 115 \\
4 & 0 & 1 & 0 & $\mathbf{9}$ & 0 & 10 \\
5 & 0 & 1 & 0 & 0 & $\mathbf{9}$ & 10 \\
\hline Total & 4 & 221 & $\mathbf{7 2}$ & 9 & 18 & $\mathbf{3 2 4}$ \\
\hline
\end{tabular}

Índice Kappa = 0,617 (Muito boa)

(b)

Observa-se que os três reservatórios possuem índices Kappa satisfatórios, ou seja, a qualidade do mapa oscilou entre Bom e Muito Bom, demonstrando a boa qualidade dos Mapas de Uso e Cobertura do Solo da Plataforma MapBiomas para a área de estudo.

\section{Métricas da Paisagem}

Neste trabalho, para avaliar a estrutura da paisagem, foram analisadas as métricas: número de polígonos (NP) e área das manchas para averiguar se houve ou não fragmentação da paisagem. De igual modo, foram observadas as métricas de relação perímetro/área e índice de forma, somada com as demais, para compreender a evolução, o tipo e a forma da fragmentação da paisagem.

Quanto às métricas, cumpre lembrar que a métrica NP quantifica as manchas de uma paisagem. Já a 
métrica relação perímetro/área está relacionada à forma do fragmento. Dessa forma, quanto menor essa relação, menor também será a borda e vice-versa. Vale ressaltar que fragmentos de formatos mais regulares têm a relação perímetro/área minimizada e, portanto, o centro da área está mais distante das bordas. Assim, a área central encontra-se isolada dos fatores externos, enquanto fragmentos de formatos mais irregulares têm maior proporção de bordas, fazendo que ocorra maior interação com a matriz circundante (PIROVANI et al., 2014). A métrica índice de forma indica o quanto irregular é uma forma. Assim, valores mais próximos de 1 são ligados a formatos mais regulares - lembrando que ações humanas tendem a provocar fragmentos mais retilíneos. Os resultados das métricas para os três reservatórios: [1] Serra Azul; [2] Vargem das Flores; e [3] Rio Manso são apresentados de forma gráfica e tabular na sequência.

\section{Reservatório Serra Azul}

A matriz da paisagem do Reservatório Serra Azul revela que a classe Pastagem/Cultura entre os anos analisados (Figura 3) detém cerca de $58 \%$ da área da microbacia. Em uma análise quantitativa de perda e ganho de área real, a classe Infraestrutura Urbana foi a que teve maior ganho, pois sua área quase que dobrou entre 2007 e 2017, passando de 435,64 ha para 849,98 ha (Tabela 9), demonstrando uma expressiva expansão urbana no período.

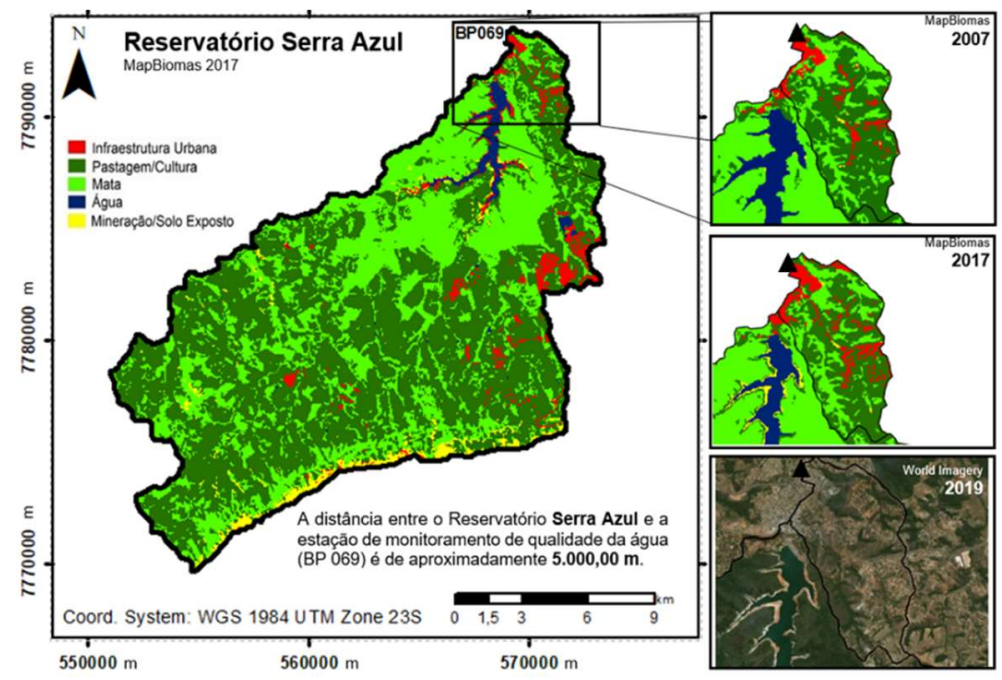

Figura 3: Bacia de contribuição do Reservatório Serra Azul.

Tabela 9: Área das classes em hectare e percentual - Reservatório Serra Azul para os anos 2007 e 2017.

\begin{tabular}{lllll}
\hline \multirow{2}{*}{ Classe/Ano } & $\mathbf{2 0 0 7}$ & $\mathbf{2 0 1 7}$ & \\
\cline { 2 - 5 } & Área (ha) & Em \% & Área (ha) & Em \% \\
\hline 1 - Infraestrutura Urbana & 435,64 & 1,59 & 849,98 & 3,10 \\
2 - Pastagem/Cultura & 15995,78 & 58,28 & 15646,53 & 57,01 \\
3 - Mata & 9689,45 & 35,30 & 9805,57 & 35,73 \\
4 - Água & 709,05 & 2,58 & 386,64 & 1,41 \\
5 - Mineração/Solo Exposto & 615,45 & 2,24 & 756,64 & 2,76 \\
\hline Total & $\mathbf{2 7 4 4 5 , 3 7}$ & $\mathbf{1 0 0 , 0 0}$ & $\mathbf{2 7 4 4 5 , 3 7}$ & $\mathbf{1 0 0 , 0 0}$ \\
\hline
\end{tabular}

Houve um aumento significativo da métrica NP da classe Infraestrutura Urbana, de 184, em 2007, para 260, em 2017, e aumento da sua área total (Tabela 10). Esse resultado aponta um possível processo de expansão urbana com leve fragmentação entre 2007 e 2017. Ao analisar as métricas para a classe Mata, é possível dizer que ela não sofreu grandes alterações ao longo dos anos 2007 e 2017, pois não houve mudança 
significativa das métricas NP, relação perímetro/área e índice de forma (Tabela 10). Ressaltamos que houve um aumento de área, porém, não houve fragmentação considerável dessa classe ao longo dos anos analisados.

Tabela 10: Métricas da paisagem do Reservatório Serra Azul para os anos 2007 (a) e 2017 (b).

\begin{tabular}{|c|c|c|c|c|c|}
\hline Classe (2007) & NP & Área $\left(\mathrm{km}^{2}\right)$ & Perímetro/ár & & Índice de forma \\
\hline 1 - Infraestrutura Urbana & 184 & 4,36 & 731,1163 & & 1,6375 \\
\hline 2 - Pastagem/Cultura & 272 & 159,96 & 645,0818 & & 1,6647 \\
\hline 3 - Mata & 605 & 96,89 & 565,6034 & & 1,7099 \\
\hline 4 - Água & 26 & 7,09 & 609,4761 & & 1,4877 \\
\hline 5 - Mineração/Solo Exposto & 169 & 6,15 & 746,4805 & & 1,6155 \\
\hline Total & 1256,00 & 274,45 & & & \\
\hline \multicolumn{6}{|l|}{ (a) } \\
\hline Classe (2017) & NP & Área $\left(\mathrm{km}^{2}\right)$ & Perímetro/área & \multicolumn{2}{|c|}{ Índice de forma } \\
\hline 1 - Infraestrutura Urbana & 260 & 8,50 & 723,4797 & \multicolumn{2}{|c|}{1,7218} \\
\hline 2 - Pastagem/Cultura & 350 & 156,46 & 669,2647 & \multicolumn{2}{|l|}{1,6799} \\
\hline 3 - Mata & 615 & 98,06 & 591,3365 & \multicolumn{2}{|l|}{1,6711} \\
\hline 4 - Água & 34 & 3,87 & 628,2459 & \multicolumn{2}{|l|}{1,3746} \\
\hline 5 - Mineração/Solo Exposto & 169 & 7,57 & 687,0682 & \multicolumn{2}{|l|}{1,6458} \\
\hline Total & 1428,00 & 274,45 & & & \\
\hline
\end{tabular}

(b)

Uma análise isolada da métrica NP de uma paisagem como um todo é insuficiente para inferir sobre a existência de fragmentação da área. A fragmentação fica evidente ao se analisar as métricas de relação perímetro/área e índice de forma. Essas métricas auxiliam na compreensão da forma dos fragmentos, sendo que quanto mais regulares, menor a pressão de borda, estando menos susceptíveis a novas fragmentações.

Sobre a relação perímetro/área, quanto menor for o seu valor, mais regular é o fragmento, sendo que essa regularidade é alcançada para valores próximos de 1 para índice de forma. Com isso, observou-se que a classe Pastagem/Cultura sofreu uma intensa fragmentação entre os anos de 2007 a 2017, pois houve diminuição de área e aumento das métricas NP, relação perímetro/área e índice de forma (Tabela 10).

\section{Reservatório Vargem das Flores}

Ao longo dos 10 anos em análise (2007 a 2017), a matriz da paisagem do Reservatório Vargem das Flores foi a classe Mata (Figura 4), já que cerca de $45 \%$ da área é composta pela referida classe (Tabela 11). A classe Infraestrutura Urbana teve o maior ganho de área, pois, quando analisamos quantitativamente a perda e o ganho real de área, ela passou de 1706,30 ha em 2007 para 2087,83 ha em 2017 (Tabela 11), demonstrando que houve expansão urbana no período. Observa-se, ainda, que quase $17 \%$ da área total da bacia de contribuição são constituídos pela classe Infraestrutura Urbana, item prejudicial à qualidade da água do reservatório.

Analisando a métrica NP, observa-se que a houve uma leve diminuição do NP total entre 2007 e 2017 (Tabela 12), demonstrando que ocorreu processo contrário à fragmentação na área do Reservatório Vargem das Flores para o período analisado. Observa-se que a classe Mata teve uma expressiva diminuição de área, perdendo 2,81 km² de área, ou seja, cerca de 2.800.000,00 m² (Tabela 12). Em uma análise geral das métricas para os dois anos, observa-se que as métricas relação perímetro/área e índice de forma aumentaram, indicando que as formas dos fragmentos se tornaram menos regulares e, consequentemente, estão mais 
susceptíveis a novas fragmentações.

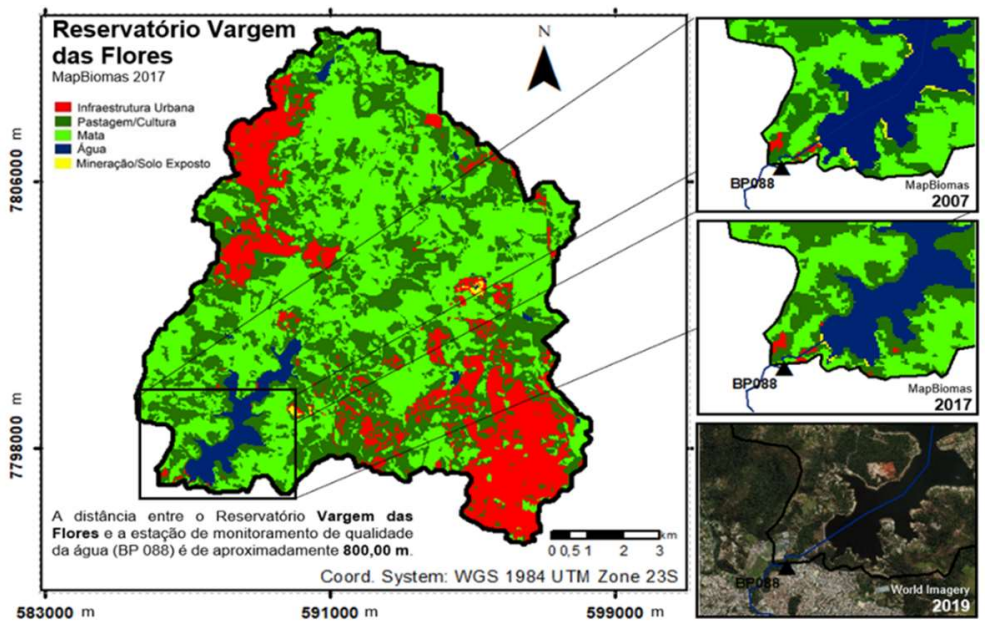

Figura 4: Bacia de contribuição do Reservatório Vargem das Flores.

Tabela 11: Área das classes em hectare e percentual - Reservatório Vargem das Flores para os anos 2007 e 2017.

\begin{tabular}{lllll}
\hline \multirow{2}{*}{ Classe/Ano } & $\mathbf{2 0 0 7}$ & $\mathbf{2 0 1 7}$ & \\
\cline { 2 - 5 } & Área (ha) & $\mathbf{E m} \%$ & Área (ha) & Em \% \\
\hline 1 - Infraestrutura Urbana & 1706,30 & 13,74 & 2087,83 & 16,82 \\
2 - Pastagem/Cultura & 4361,10 & 35,13 & 4411,77 & 35,54 \\
3 - Mata & 5813,34 & 46,83 & 5531,92 & 44,56 \\
4 - Água & 507,86 & 4,09 & 364,55 & 2,94 \\
5 - Mineração/Solo Exposto & 25,78 & 0,21 & 18,30 & 0,15 \\
\hline Total & $\mathbf{1 2 4 1 4 , 3 7}$ & $\mathbf{1 0 0 , 0 0}$ & $\mathbf{1 2 4 1 4 , 3 7}$ & $\mathbf{1 0 0 , 0 0}$ \\
\hline
\end{tabular}

Tabela 12: Métricas da paisagem do Reservatório Vargem das Flores para os anos 2007 (a) e 2017 (b).

\begin{tabular}{lllll}
\hline Classe (2007) & NP & Área $\left(\mathbf{k m}^{\mathbf{2}}\right)$ & Perímetro/área & Índice de forma \\
\hline 1 - Infraestrutura Urbana & 178 & 17,06 & 726,8685 & 1,6751 \\
2 - Pastagem/Cultura & 394 & 43,61 & 609,7148 & 1,7318 \\
3 - Mata & 281 & 58,13 & 662,7097 & 1,5541 \\
4 - Água & 22 & 5,08 & 471,2184 & 1,4212 \\
5 - Mineração/Solo Exposto & 5 & 0,26 & 379,3967 & 1,5064 \\
\hline Total & $\mathbf{8 8 0 , 0 0}$ & $\mathbf{1 2 4 , 1 4}$ & & \\
\cline { 1 - 2 } & &
\end{tabular}

(a)

\begin{tabular}{lllll}
\hline Classe (2017) & NP & Área $\left.\mathbf{( k m}^{2}\right)$ & Perímetro/área & Índice de forma \\
\hline 1 - Infraestrutura Urbana & 186 & 20,88 & 718,0513 & 1,7119 \\
2 - Pastagem/Cultura & 395 & 44,12 & 668,7536 & 1,7353 \\
3 - Mata & 240 & 55,32 & 610,5753 & 1,6033 \\
4 - Água & 23 & 3,64 & 513,8158 & 1,4019 \\
5 - Mineração/Solo Exposto & 8 & 0,18 & 762,8223 & 1,5107 \\
\hline Total & $\mathbf{8 5 2 , 0 0}$ & $\mathbf{1 2 4 , 1 4}$ & & \\
\cline { 1 - 2 } & &
\end{tabular}

(b)

\section{Reservatório Rio Manso}

A matriz da paisagem do reservatório é a classe Pastagem/Cultura (Figura 5), pois cerca de 65\% da área é composta pela referida classe (Tabela 13). Observa-se que a área da classe Infraestrutura Urbana permaneceu estável no período analisado (Tabela 13), demonstrando que não houve expansão urbana significativa entre 2007 e 2017. Outro ponto observado é que somente $1 \%$ da área de contribuição do reservatório é constituído pela classe Infraestrutura Urbana, ou seja, esse reservatório recebeu baixa carga 
de poluição difusa proveniente da urbanização.

Tabela 13: Área das classes em hectare e percentual - Reservatório Rio Manso para os anos 2007 e 2017.

\begin{tabular}{lllll}
\hline \multirow{2}{*}{ Classe/Ano } & $\mathbf{2 0 0 7}$ & $\mathbf{2 0 1 7}$ \\
\cline { 2 - 5 } & Área (ha) & Em \% & Área (ha) & Em \% \\
\hline 1 - Infraestrutura Urbana & 572,78 & 0,85 & 652,40 & 0,97 \\
2 - Pastagem/Cultura & 45094,75 & 67,04 & 43652,90 & 64,90 \\
3 - Mata & 16508,22 & 24,54 & 18328,35 & 27,25 \\
4 - Água & 1010,27 & 1,50 & 911,65 & 1,36 \\
5 - Mineração/Solo Exposto & 4080,30 & 6,07 & 3721,02 & 5,53 \\
\hline Total & $\mathbf{6 7 2 6 6 , 3 1}$ & $\mathbf{1 0 0 , 0 0}$ & $\mathbf{6 7 2 6 6 , 3 1}$ & $\mathbf{1 0 0 , 0 0}$ \\
\hline
\end{tabular}

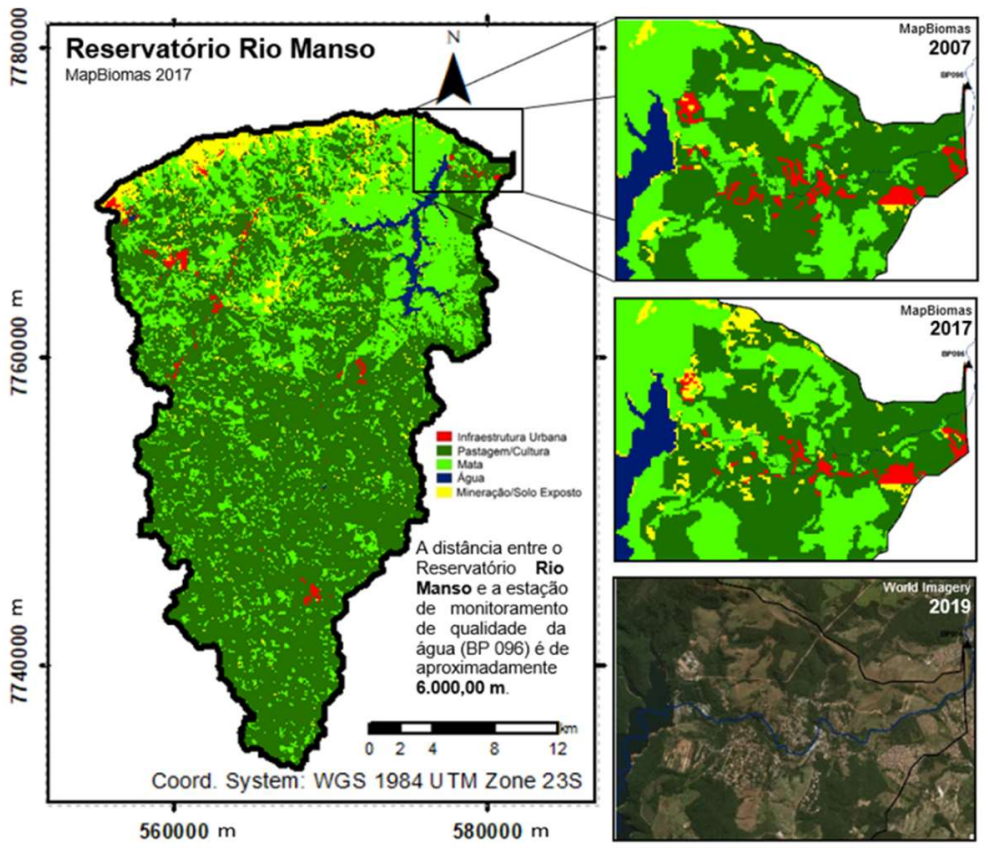

Figura 5: Bacia de contribuição do Reservatório Rio Manso.

A métrica Número de Polígono - NP total permaneceu quase estável no período analisado. Observouse, ainda, um aumento de área da classe Mata e uma diminuição de área da classe Pastagem/Cultura (Tabela 14). Esses resultados sugerem que não ocorreu fragmentação da área e que houve uma eventual regeneração na paisagem com leve expansão urbana entre 2007 e 2017. Ao analisar a classe Mineração/Solo Exposto, observa-se que houve um decréscimo de área com redução significativa da métrica NP entre os anos 2007 e 2017, ratificando a ideia de regeneração, pois, áreas não vegetadas deram origem a outras áreas vegetadas no período analisado. Analisando a classe Água para os três reservatórios, pode-se observar que houve diminuição significativa de área para a referida classe entre 2007 e 2017, o que significa um reflexo da crise hídrica observada naquele período. A menor perda de área foi observada no reservatório Rio Manso. Um resumo dos principais resultados da pesquisa é apresentado a seguir (Tabela 15):

Tabela 14: Métricas da paisagem do Reservatório Rio Manso para os anos 2007 (a) e 2017 (b).

\begin{tabular}{lllll}
\hline Classe (2007) & NP & Área $\left.\mathbf{( k m}^{\mathbf{2}}\right)$ & Perímetro/área & Índice de forma \\
\hline 1 - Infraestrutura Urbana & 205 & 5,73 & 729,2984 & 1,6528 \\
2 - Pastagem/Cultura & 506 & 450,95 & 624,0204 & 1,6316 \\
3 - Mata & 1732 & 165,08 & 551,5239 & 1,56 \\
4 - Água & 16 & 10,10 & 635,9316 & 1,6695 \\
5 - Mineração/Solo Exposto & 1127 & 40,80 & 699,7913 & 1,5621 \\
\hline
\end{tabular}

Total $3586,00 \quad 672,66$

(a)

$\begin{array}{llll}\text { Classe (2017) NP } & \text { Área }\left(\mathrm{km}^{2}\right) & \text { Perímetro/área } & \text { Índice de forma }\end{array}$




\begin{tabular}{lllll}
1 - Infraestrutura Urbana & 212 & 6,52 & 724,6023 & 1,642 \\
2 - Pastagem/Cultura & 563 & 436,53 & 641,4801 & 1,7305 \\
3 - Mata & 1833 & 183,28 & 575,4028 & 1,587 \\
4 - Água & 20 & 9,12 & 636,0341 & 1,6756 \\
5 - Mineração/Solo Exposto & 976 & 37,21 & 719,1351 & 1,5508 \\
\hline Total & $\mathbf{3 6 0 4 , 0 0}$ & $\mathbf{6 7 2 , 6 6}$ & & \\
\cline { 1 - 3 }
\end{tabular}

(b)

Tabela 15: Resumo dos resultados para os três reservatórios (Serra Azul, Vargem das Flores e Rio Manso).

\begin{tabular}{|c|c|c|c|c|c|c|c|}
\hline \multirow{2}{*}{\multicolumn{2}{|c|}{ RESERVATÓRIO }} & \multicolumn{2}{|c|}{ Serra Azul (BP069) } & \multicolumn{2}{|c|}{$\begin{array}{l}\text { Vargem das } \text { Flores } \\
\text { (BP088) }\end{array}$} & \multicolumn{2}{|c|}{ Rio Manso (BP096) } \\
\hline & & 2007 & 2017 & 2007 & 2017 & 2007 & 2017 \\
\hline \multicolumn{2}{|l|}{ IQA (IGAM) } & $\begin{array}{l}37 \\
\text { (Ruim) }\end{array}$ & $\begin{array}{l}54 \\
\text { (Médio) }\end{array}$ & 90 (Bom) & 83 (Bom) & $\begin{array}{l}54 \\
\text { (Médio) }\end{array}$ & $\begin{array}{l}40 \\
\text { (Ruim) }\end{array}$ \\
\hline \multirow[t]{2}{*}{ Igarapé } & Coleta (IN015*) & $21,33 \%$ & $42,57 \%$ & & & & \\
\hline & Tratamento (IN016**) & $0 \%$ & $0 \%$ & & & & \\
\hline \multirow[t]{2}{*}{ Juatuba } & Coleta (IN015*) & $32,23 \%$ & $26,87 \%$ & & & & \\
\hline & Tratamento (IN016**) & $5,91 \%$ & $58,6 \%$ & & & & \\
\hline \multirow[t]{2}{*}{ Mateus Leme } & Coleta (IN015*) & - & $42,66 \%$ & & & & \\
\hline & Tratamento (IN016**) & - & $76,17 \%$ & & & & \\
\hline \multirow[t]{2}{*}{ Betim } & Coleta (IN015*) & & & $66,49 \%$ & $56,07 \%$ & & \\
\hline & Tratamento (IN016**) & & & $3,99 \%$ & $91,99 \%$ & & \\
\hline \multirow[t]{2}{*}{ Contagem } & Coleta (IN015*) & & & $61,56 \%$ & $71,91 \%$ & & \\
\hline & Tratamento (IN016**) & & & $44,1 \%$ & $95,74 \%$ & & \\
\hline \multirow[t]{2}{*}{ Bonfim } & Coleta (IN015*) & & & & & $54,06 \%$ & $60,21 \%$ \\
\hline & Tratamento (IN016**) & & & & & $0 \%$ & $0 \%$ \\
\hline \multirow[t]{2}{*}{ Brumadinho } & Coleta (IN015*) & & & & & $7,14 \%$ & $61,95 \%$ \\
\hline & Tratamento (IN016**) & & & & & $100 \%$ & $18,56 \%$ \\
\hline \multirow[t]{2}{*}{ Crucilândia } & Coleta (IN015*) & & & & & - & $100 \%$ \\
\hline & Tratamento (IN016**) & & & & & - & $50 \%$ \\
\hline \multirow[t]{2}{*}{ Itatiaiuçu } & Coleta (IN015*) & & & & & - & $79,27 \%$ \\
\hline & Tratamento (IN016**) & & & & & - & $0 \%$ \\
\hline \multirow[t]{2}{*}{ Manso } & Coleta $($ IN015*) & & & & & - & - \\
\hline & Tratamento (IN016**) & & & & & - & - \\
\hline \multicolumn{2}{|c|}{$\begin{array}{l}\text { Matriz da Paisagem } \\
\text { Área média 2007/2017 (\%) }\end{array}$} & \multicolumn{2}{|c|}{$\begin{array}{l}\text { Pastagem/Cultura } \\
(58 \%)\end{array}$} & \multicolumn{2}{|c|}{ Mata (46\%) } & \multicolumn{2}{|c|}{$\begin{array}{l}\text { Pastagem/Cultura } \\
(66 \%)\end{array}$} \\
\hline \multicolumn{2}{|c|}{$\begin{array}{l}\text { Infraestrutura Urbana } \\
\text { Área (\%) }\end{array}$} & $1,59 \%$ & $3,10 \%$ & $13,7 \%$ & $16,8 \%$ & $0,85 \%$ & $0,97 \%$ \\
\hline \multicolumn{2}{|c|}{$\begin{array}{l}\text { Mata } \\
\text { Área (\%) }\end{array}$} & $35,3 \%$ & $35,7 \%$ & $46,8 \%$ & $44,6 \%$ & $24,5 \%$ & $27,3 \%$ \\
\hline \multicolumn{2}{|c|}{$\begin{array}{l}\text { Pastagem/Cultura } \\
\text { Área (\%) }\end{array}$} & $58,3 \%$ & $57,0 \%$ & $35,1 \%$ & $35,5 \%$ & $67,0 \%$ & $64,9 \%$ \\
\hline \multicolumn{2}{|c|}{$\begin{array}{l}\text { Distância do reservatório ao ponto de } \\
\text { monitoramento }\end{array}$} & \multicolumn{2}{|l|}{$5 \mathrm{~km}$} & \multicolumn{2}{|l|}{$0,8 \mathrm{~km}$} & \multicolumn{2}{|l|}{$6 \mathrm{~km}$} \\
\hline \multicolumn{2}{|c|}{ Área da bacia de contribuição } & \multicolumn{2}{|c|}{$274,45 \mathrm{~km}^{2}$} & \multicolumn{2}{|c|}{$124,14 \mathrm{~km}^{2}$} & \multicolumn{2}{|c|}{$672,66 \mathrm{~km}^{2}$} \\
\hline
\end{tabular}

*IN015 - Índice de coleta de esgoto e **IN016 - Índice de tratamento de esgoto.

\section{DISCUSSÃO}

As ações antrópicas, dentre elas, a expansão urbana e a fragmentação florestal, modificaram o uso e a ocupação do solo ao passar dos anos. Esta modificação altera sensivelmente os processos físico-químicos e biológicos dos sistemas naturais. É sabido que os ecossistemas dos reservatórios situados em bacias urbanas e periurbanas são muito frágeis e particularmente vulneráveis às mudanças que ocorrem em sua bacia hidrográfica. $\mathrm{O}$ aumento de áreas impermeáveis, as mudanças no uso do solo e o crescimento populacional sem infraestrutura sanitária adequada resultam no aumento do volume e da carga poluidora do escoamento superficial, cujo destino é o meio aquático receptor (ALBERTI et al., 2007; VIEIRA et al., 2009). Estes fatores fazem parte da realidade das análises ambientais -objetivo principal do presente estudo- e são observados na área de estudo. 
Com relação à área escolhida para o estudo, a crise hídrica ocorrida entre os anos de 2014 a 2016 afetou fortemente a Região Metropolitana de Belo Horizonte. Nesse contexto, torna-se relevante advertir sobre a importância desses reservatórios como estratégia para o abastecimento da região. Logo, dentro do contexto de ameaça aos recursos hídricos, em especial às bacias produtoras de água, é importante demonstrar como a ciência pode contribuir na gestão eficiente dos recursos hídricos de modo a garantir a disponibilidade desses recursos em quantidade e qualidade.

Em relação ao Índice de Qualidade da Água (IQA) utilizado no estudo, apesar de ser uma simplificação da qualidade da água, ele permite avaliar a qualidade da água bruta visando ao seu uso para abastecimento público (após o tratamento), sendo que os nove parâmetros utilizados no cálculo são, em sua maioria, indicadores de contaminações causadas pelo lançamento indevido de esgoto doméstico.

Quanto aos impactos da expansão urbana e da fragmentação florestal na qualidade da água, ponderamos que o reservatório que apresentou melhores índices IQA (Bom) é o Vargem das Flores, mesmo tendo o maior percentual de área urbana ( $16 \%$ da área) e vários conflitos de uso do solo no entorno do reservatório. No entanto, é o único reservatório cuja matriz da paisagem é a classe Mata (que ocupa $46 \%$ da área). Além disso, os municípios da bacia hidrográfica de contribuição desse reservatório apresentam os melhores índices de coleta e tratamento de esgoto. Nesse quadro, dois fatores, não exploradas nesse estudo, também podem auxiliar na interpretação do melhor desempenho de Vargem das Flores: 1) a cobertura florestal pode servir como uma espécie de sumidouro para alguns poluentes da água, logo a qualidade da água tende a se manter melhor à medida que a cobertura florestal aumente; e 2) o barramento pode funcionar como um filtro para os resíduos, já que a distância da estação de monitoramento ao reservatório Vargem das Flores é de $800 \mathrm{~m}$ (enquanto nos outros reservatórios essa distância é superior a 5 quilômetros). Entretanto, ressalta-se que houve uma redução do IQA entre 2007 e 2017 para o reservatório Vargem das Flores, possivelmente por conta da diminuição da classe Mata e o aumento da Infraestrutura Urbana.

Já os reservatórios de Serra Azul e Rio Manso apresentam índices de IQA pouco satisfatórios, oscilando entre Ruim e Bom, fato que pode ser justificado devido à matriz da paisagem ser a classe Pastagem/Cultura. A baixa qualidade do índice pode estar relacionada à agricultura, que influencia fortemente na concentração de nitrogênio, fósforo e sólidos suspensos totais, além das cargas de sedimentos nos cursos de água e os solos mais expostos, que permitem maior carreamento de partículas e impurezas para os corpos hídricos no período de precipitação, influenciando negativamente na qualidade da água. Outro fator relevante são os baixos índices de coleta e tratamento de esgoto dos municípios das bacias hidrográficas desses reservatórios.

Contudo, a relação entre o uso do solo e a qualidade da água não é constante, isso porque as bacias hidrográficas possuem características diferentes, constituindo ambientes únicos. Além disso, a escala geográfica e o relevo têm forte influência nesse relacionamento. Para uma análise mais detalhada deve-se, portanto, considerar as particularidades do local do estudo. Esses resultados, somados a outras informações, certamente permitiriam aos órgãos públicos (executivo e o ministério público) tomar decisões mais assertivas no que diz respeito à gestão e fiscalização dos recursos hídricos. 
Outro ponto importante é o fato de este estudo ter utilizado apenas software e dados geográficos gratuitos, onde se preocupou com o controle de qualidade temática das imagens. Desta forma, o emprego de geotecnologias pode prover materiais de qualidade e análises que permitam tomar melhores decisões quanto à gestão eficiente dos recursos hídricos, visando garantir a disponibilidade desses recursos em quantidade e qualidade.

\section{CONCLUSÕES}

A partir dos estudos realizados e dos resultados encontrados, pode-se chegar às seguintes conclusões: 1) Os mapas classificados da Plataforma MapBiomas são satisfatórios no que diz respeito à qualidade temática (índice Kappa), demonstrando a viabilidade de sua utilização em análises ambientais; 2) As métricas utilizadas neste estudo foram satisfatórias no que diz respeito à análise da expansão urbana e fragmentação florestal, evidenciando sua importância no processo de reconhecimento e análise da dinâmica de mudanças de uso do solo nas bacias estudadas; 3) Esta pesquisa apresenta um diagnóstico dos impactos das alterações do uso e ocupação do solo na qualidade da água, bem como a relação positiva entre a cobertura florestal na qualidade da água. Os resultados serviriam para nortear ações governamentais no sentido de preservação e gestão dos recursos hídricos; 4) Para uma avaliação mais aprofundada da relação entre o uso e ocupação do solo na qualidade da água, é necessário também considerar outros fatores, como a caracterização física, biótica e socioeconômica dos municípios que fazem parte da bacia, bem como das atividades existentes na área. 5) Quanto aos desafios do uso da geotecnologia na gestão dos recursos hídricos, cumpre destacarmos que essa metodologia supriu com eficiência o objetivo proposto de analisar os impactos do uso e ocupação do solo na qualidade da água, contornando, de forma alternativa, os altos custos com o uso imagens privadas e software licenciados.

AGRADECIMENTOS: Ao Centro Federal de Educação Tecnológica de Minas Gerais - CEFET/MG, e ao CNPq.

\section{REFERÊNCIAS}

ALBERTI, M.; BOOTH D.; HILL, K.; COBURN, B.; AVOLIO, C.; COES, S.; SPIRANDELLI, D.. The impact of urban patterns on aquatic ecosystems: An empirical analysis in Puget lowland sub-basins. Landscapeand Urban Planning, v.80, n.4, p.345361, 2007.

BARBOSA, V. L.; NASCIMENTO JÚNIOR, A. F.. Paisagem, ecologia urbana e planejamento ambiental. Geografia, Londrina, v.18, n.2, 2009.

BEZERRA, C. G.; SANTOS, A. R.; PIROVANI, D. B.; PIMENTEL; L. B.; EUGENIO, F. C.. Estudo da fragmentação florestal e ecologia da paisagem na sub-bacia hidrográfica do Córrego Horizonte, Alegre, ES. Revista Espaço \& Geografia, v.14, n.2, p.257-277, 2011

BINKLEY, D.; BURNHAM, H.; ALLEN, H. L.. Water quality impacts of forest fertilization with nitrogen and phosphorus. Forest Ecology and Management, v.121, n.3, p.191-213, 1999.
CAREY, R. O.; MIGLIACCIO, K. W.; LI, Y. C.; SCHAFFER, B.; KIKER, G. A.; BROWN, M. T.. Land use disturbance indicators and water quality variability in the Biscayne Bay Watershed, Florida. Ecolog. Indic., v.11, p.1093-1104, 2011.

CARVALHO, R. F.. Avaliação do uso e ocupação do solo na bacia do ribeirão Serra Azul e as consequências no reservatório de abastecimento da COPASA - MG. Dissertação (Mestrado em Geografia) - Universidade Federal de Minas Gerais, Belo Horizonte, 2002.

COPASA. Companhia de Saneamento de Minas Gerais. Nível dos Reservatórios. Belo Horizonte: COPASA, 2017.

COSTA, F. B.; FERREIRA, V. O.. Análise de Parâmetros que Compõem o Índice de Qualidade das Águas (IQA) na Porção Mineira da Bacia do Rio Paranaíba. Observatorium: Revista Eletrônica de Geografia, v.7, n.18, p.22-47, 2015. 
COUTO, P.. Análise factorial aplicada a métricas da paisagem definidas em Fragstats. Investigação Operacional, v.24, p.109-137, 2004.

FENG, H.; HAN, X.; ZHANG, W.; YU, L.. A preliminary study of heavy metal contamination in Yangtze River intertidal zone due to urbanization. Marine pollution bulletin, v.49, n.1112, p.910-915, 2004.

FISHER, D. S.; STEINER, J. L.; ENDALE, D. M.; STUEDEMANN, J. A.; SCHOMBERG, H. H.; FRANZLUEBBERS, A. J.; WILKINSON, S. R.. The relationship of land use practices to surface water quality in the Upper Oconee Watershed of Georgia. Forest Ecologyand Management, v.128, n.1-2, p.39-48, 2000.

GOMES, L. N. L.. Estudo da associação entre parâmetros bióticos e abióticos e a ocorrência de florações de cianobactérias no reservatório de Vargem das Flores/MG Tese (Doutorado em Saneamento, Meio Ambiente e Recursos Hídricos) - Universidade Federal de Minas Gerais Belo Horizonte, 2008.

IBGE. Instituto Brasileiro de Geografia e Estatística. Manual Técnico de Uso da Terra. Manuais técnicos em geociências. Rio de Janeiro: IBGE, 2013.

IGAM. Instituto Mineiro de Gestão das Águas. Projeto Águas de Minas: qualidade das águas superficiais em 2002. Belo Horizonte: IGAM, 2003.

IGAM. Instituto Mineiro de Gestão das Águas. Qualidade das águas superficiais de Minas Gerais em 2007: resumo executivo. Belo Horizonte: IGAM, 2008.

IGAM. Instituto Mineiro de Gestão das Águas. Qualidade das águas superficiais de Minas Gerais em 2017: resumo executivo. Belo Horizonte: IGAM, 2018.

LKR, A.; SINGH, M. R.; PURO, N.. Assessment ofwaterquality status ofDoyang River, Nagaland, India, using Water Quality Index. Applied Water Science, v.10, n.46, 2020.

METZGER, J. P.. O que é ecologia de paisagens?. Biota Neotrópica, v.1, n.1-2, p.1-9, 2001.

MOREIRA, M. A.. Fundamentos do sensoriamento remoto e metodologia de aplicação. 2 ed. Viçosa: UFV, 2003.

BELO HORIZONTE. Plano Diretor de Desenvolvimento Integrado da Região Metropolitana de Belo Horizonte (PDDIRMBH). Rio Manso/MG: Processo de revisão: Plano Diretor. Belo Horizonte, 2017.
PIROVANI, D. B.; SILVA, A. G.; SANTO, A. R.; CECÍLIO, R. A.; GLERIANI, J. M.; MARTINS, S. V.. Análise espacial de fragmentos florestais na Bacia do Rio Itapemirim, ES. Rev. Árvore, v.38, n.2, p.271-281, 2014.

ROCHA, C. H. B.. Geoprocessamento: tecnologia transdisciplinar. 2 ed. Juiz de Fora: Autor, 2002.

SISEMA. Infraestrutura de dados espaciais do sistema estadual de meio ambiente e recursos hídricos. Belo Horizonte: SISEMA, 2019.

SAITO, N. S.; MOREIRA, M. A.; SANTOS, A. R.; EUGENIO, F. C.; FIGUEIREDO, A. C.. Geotecnologia e Ecologia da Paisagem no Monitoramento. Floresta e Ambiente, v.23, n.2, 2016.

SILVA, F. B.; MARQUE, T. S.; DELGADO, C.. Processos de expansão urbana e mudanças na paisagem: ensaio metodológico (1950-2000). Revista da Faculdade de Letras, Geografia, v.1, n.3, p.161-183, 2012.

SNIS. Sistema Nacional de Informações sobre Saneamento. Série Histórica. Brasilia: SNIS, 2020.

URIARTE, M.; YACKULIC, C. B.; LIM, Y.; ARCE-NAZARIO, J.. Influence of land use on water quality in a tropical landscape: a multi-scale analysis. Landscape Ecol., v.26, p.1151-1164, 2011.

VIEIRA, P. C.; SEIDL, M.; NASCIMENTO, N. E.; VON SPERLING M.. Avaliação de fluxo de poluentes em tempo seco e durante eventos de chuva em uma microbacia urbanizada no município de Belo Horizonte. In: RIGHETTO, A. M.. Manejo de águas pluviais urbanas. Rio de Janeiro: $A B E S$, 2009. p.346-366.

VON SPERLING, E.; FERREIRA, A. C. S.; GOMES, L. N. L.. Comparative eutrophication development in two Brazilian water supply reservoirs with respect to nutrient concentrations and bacteria growth. Desalination, v.226, p.169-174, 2008.

WILSON, C. O.; WENG, Q.. Simulating the impacts of future land use and climate changes on surface water quality in the Des Plaines River watershed, Chicago Metropolitan Statistical Area, Illinois. Sci. Total Env., v.409, p.4387-4405, 2011.

YE, Y.; HE, X.; CHEN, W.; YAO, J.; YU, S.; JIA, L.. Seasonal water quality upstream of Dahuofang Reservoir, China: the effects of land use type at various spatial scales. Clean: Soil, Air, Water, v.42, n.10, p.1423-1432, 2014

A CBPC - Companhia Brasileira de Produção Científica (CNPJ: 11.221.422/0001-03) detém os direitos materiais desta publicação. Os direitos referem-se à publicação do trabalho em qualquer parte do mundo, incluindo os direitos às renovações, expansões e disseminações da contribuição, bem como outros direitos subsidiários. Todos os trabalhos publicados eletronicamente poderão posteriormente ser publicados em coletâneas impressas sob coordenação da Sustenere Publishing, da Companhia Brasileira de Produção Científica e seus parceiros autorizados. Os (as) autores (as) preservam os direitos autorais, mas não têm permissão para a publicação da contribuição em outro meio, impresso ou digital, em português ou em tradução. 